\title{
Manipulação, Contramanipulação e Persuasão no Discurso Presidencial: Mecanismos Circunstanciais ou sempre Atuais?
}

(Manipulation, Countermanipulation and Persuasion in the Presidential Discourse: Circumstantial or ever Present Mechanisms?)

\author{
Lidia Almeida BARros, \\ Diva Cardoso de Camargo, \\ Eli Nazareth BECHARA \\ Daniel FONSECA \\ Evelyne PAPE \\ Sulivan Pereira Brito
}

\begin{abstract}
This study makes an analysis of persuasion, manipulation and countermanipulation processes present in a presidential speech. It aims at understanding how the discourse enunciators organise the discourse in order to obtain the enunciatee's acceptance (the Brazilian society). From a methodological point of view, we analysed space- and time-shiftings in and out, the creation of value objects and anti-subjects, and mechanisms used by the enunciator to establish a contract with the enunciatee. Opposition and government are invested with values as loss to the nation and national understanding. This study intends to offer some parameters that can be used to establish comparisons between similar discourses.

KEY-WORDS: Socio-semiotics; Political discourse; Persuasion; Manipulation.

RESUMO: Este trabalho procede a uma análise dos processos de persuação, manipulação e contramanipulação presentes em um pronunciamento presidencial ${ }^{1}$. Objetiva compreender como os enunciadores do discurso organizam o mesmo no sentido de obter a adesão do enunciatário (sociedade brasileira). Do ponto de vista metodológico, são analisadas
\end{abstract}

1 A fim de facilitar a leitura deste artigo, definiremos, em notas de rodapé, alguns conceitos da Sociossemiótica nele empregados.

D.E.L.T.A., 19:1, 2003 (31-63) 
as embreagens e debreagens espaço-temporais, a criação de objetos de valor e anti-sujeitos, mecanismos empregados pelo enunciador para estabelecer um contrato com o enunciatário. Oposição e governo são investidos de valores como prejuízo à naçãa e entendimento nacional. Este estudo pretende fornecer alguns parâmetros para comparação entre discursos de mesma natureza.

PalaVRas-CHAVE: Sociossemiótica; Discurso político; Persuasão; Manipulação.

\section{Introdução}

O discurso político é normalmente marcado por processos de persuasão, manipulação e contramanipulação. Os sujeitos ${ }^{2}$ enunciadores valemse de vários mecanismos discursivos para atingir seus objetivos. Mudam os temas, as situações políticas, os contextos sociais e os sujeitos, mas alguns recursos discursivos se mantêm.

Em 1987, o Presidente José Sarney confrontou-se com o problema da duração do mandato. Dirigiu-se, então, à nação, no sentido de estabelecer um contrato com esse enunciatário, pretendendo, assim, angariar a adesão da população à sua proposta de mandato de cinco anos. Tempos depois, o Presidente Fernando Henrique Cardoso empenhou-se em mudar a Constituição para poder se candidatar à reeleição. Também nesse caso procurou convencer a sociedade brasileira a aderir à sua proposta.

Assim como Sarney e FHC, todos os chefes do Executivo, em uma situação ou outra, dirigem-se ao povo em busca de apoio a um projeto político e, para tanto, recorrem a pronunciamentos. Tais discursos são sempre marcados por processos de sedução, de persuasão, de manipulação e de contramanipulação. Podemos nos interrogar como esses processos se manifestam nesses pronunciamentos. Que características discursivas estes teriam em comum?

2 Sujeito (S) consiste num "ser" ou num "princípio ativo" que pode possuir qualidades e capacidade de efetuar atos. O sujeito discursivo pode ocupar diferentes posições actanciais sem, no entanto, perder sua identidade ao longo do discurso. Em um esquema narrativo, o sujeito pode vir a ter de enfrentar um anti-sujeito (S) que se lhe opõe de alguma maneira. Em determinadas condições, o sujeito pode ser chamado de Destinatário-sujeito, como veremos na nota 3. 
Nossa proposta de análise sociossemiótica de um pronunciamento de Sarney, que aborda a questão da duração do mandato presidencial, tem por objetivo verificar como o destinador ${ }^{3}$, no decorrer do discurso, persegue seus fins por meio do encadeamento de programas narrativos ${ }^{4}$.

Observamos em nosso estudo que o discurso é apenas um momento dentro de um processo em curso, que se iniciou no passado, percorreu o presente (1987) e se projetou para o futuro (mais dois anos de poder). A situação da época é apresentada como insustentável e a necessidade de soluções é utilizada como argumento para credenciar o Presidente a tomar decisões. Esse processo é conduzido por embreagens e debreagens 5 espaçotemporais e é nesse mesmo mecanismo que Sarney se apóia para estabelecer um contrato com o povo brasileiro no sentido de persuadi-lo a aderir a um pacto político de apoio ao governo. Por meio de oposições, Sarney cria anti-objetos de valor ${ }^{6}$ e anti-sujeitos. Procurando sincretismo com o povo e alinhando-se a objetos de valor, o Presidente apresenta a oposição ao governo como prejuízo à nação e a adesão à sua vontade como entendimento nacional. Aqui a intimidação, dentro do processo manipulatório, é largamente utilizada, porém em alguns momentos o próprio Sarney acaba, no nível discursivo, na trincheira oposta.

Nosso trabalho procede a uma análise detalhada do pronunciamento de Sarney relativo à duração do mandato. Pretendemos, dessa maneira,

\footnotetext{
3 Escritos com letra minúscula, destinador e destinatário são tomados neste artigo em sua acepção geral, ou seja, como dois actantes da comunicação. Em outras teorias da informação, são chamados emissor e receptor. Em Sociossemiótica, quando os actantes são implícitos e logicamente pressupostos são chamados de enunciador e enunciatário. Por outro lado, quando explicitados e reconhecíveis no discurso enunciado, são denominados narrador e narratário. Por sua vez, escritos com letra maiúscula, Destinador (D) e Destinatário são instâncias actanciais que mantêm, respectivamente, uma relação hiperonímica e hiponímica. O Destinador é aquele que investe o Destinatário-sujeito de competência modal, comunica-lhe os valores em jogo e sanciona sua performance.

4 Programa narrativo (PN) é uma seqüência de enunciados em que o enunciado de fazer rege o de estado, ou melhor, o PN constitui uma mudança de estado provocada por um sujeito.

5 Debreagem actancial consiste na disjunção, em um primeiro momento, do sujeito da enunciação e na projeção de um "não-eu" no enuncidado. Embreagem, por oposição à debreagem, consiste no retorno à enunciação, produzindo, mesmo que de modo implícito, uma identificação entre o sujeito da enunciação e do enunciado. O mesmo tipo de processo pode ocorrer com categorias de tempo e espaço. Toda embreagem pressupõe uma operação anterior de debreagem.

6 Objeto - ou objeto de valor (Ov) - é o lugar de investimento de valores ou de determinações que pode estar em conjunção ou disjunção com o sujeito. Por oposição, o anti-objeto de valor $\overline{\mathrm{Ov}}$ é investido de valores ou de determinações negativas.
} 
dar uma contribuição à compreensão do funcionamento dos recursos discursivos utilizados nos pronunciamentos presidenciais em geral. Almejamos, assim, fornecer alguns parâmetros de comparação para outras análises de discursos políticos.

\section{Organização do discurso}

"Brasileiras e brasileiros, boa noite". Assim se inicia o discurso do Presidente Sarney no dia 18 de maio de 1987. Ao pronunciar essas palavras, Sarney busca atrair a atenção dos ouvintes e telespectadores do Brasil todo para seu pronunciamento. Explica: "Estou aqui para um comunicado da maior importância para os rumos políticos de nosso país". Desse modo, estabelece-se, no eixo da comunicação, um destinador (com letra minúscula) - Sarney -, uma mensagem (comunicado) e um destinatário (também com letra minúscula) - brasileiras e brasileiros. A função conativa predomina. Semioticamente, estabelece-se um FAZER SABER e, no plano narrativo, Sarney é o narrador.

Contato estabelecido, segue a mensagem pelos meios de comunicação (TV e rádio), num continuum, chegando aos ouvidos do destinatário. Para efeito de análise, recortaremos a mensagem em segmentos, a fim de melhor se compreender o que se diz e o que se quer dizer, ou seja, para um estudo mais aprofundado do discurso do Presidente Sarney. O critério para isso utilizado se baseou na repetição de vocativos e/ou temas ("Brasileiras e brasileiros"). Também numeramos os parágrafos do discurso pronunciado por Sarney, afim de facilitar a localização dos dados a que nos referiremos ao longo do nosso trabalho. O procedimento anafórico assegura o encadeamento das seqüências narrativas durante o correr do discurso. É com base nele que a análise será feita.

O primeio segmento se caracteriza pela modalizaçãa ${ }^{7}$ do sujeito principal de toda a narrativa - Sarney (S1).

\footnotetext{
7 Modalização é uma relação predicativa que pode incidir sobre o sujeito e o objeto. De acordo com a natureza do enunciado a ser modalizado, pode-se determinar duas grandes classes de modalizações: a do "ser" e a do "fazer".
} 
O segundo apresenta os problemas que o sujeito e toda a nação enfrentam e estabelece um objeto de valor - estabelecimento da duração do mandato presidencial - que deverá ser o alvo da busca de Sarney (S1) durante boa parte do discurso. Em "Com a franqueza com que sempre me dirigi às brasileiras e brasileiros (...)", "franqueza" dá continuidade à modalização de $\mathrm{S} 1$, que percorreu os onze primeiros parágrafos. A partir daí, são apresentados os problemas dos quais S1 quer tratar (do $12^{\circ}$ ao $21^{\circ}$ paragráfo).

O terceiro segmento caracteriza-se pela decisão tomada por S1. Na passagem do segundo para o terceiro segmento, novamente "Brasileiras e brasileiros" são evocados; e "Venho falar claramente ${ }^{8}$ sobre este assunto" retoma a modalização de $\mathrm{S} 1$, como instrumento de introdução da decisão tomada.

O quarto segmento tem seu início marcado pela recorrência do vocativo "Brasileiras e brasileiros". Neste segmento um novo programa narrativo é desenvolvido, tendo como Ov não mais a duração do mandato presidencial, mas o regime governamental.

O quinto segmento é o fecho do discurso. Na passagem do quarto segmento para este, o procedimento anafórico é novamente utilizado: retoma-se o tema do segundo segmento, a apresentação dos problemas do país, no qual se situam as considerações sobre "crise e mudança". "Boa noite" fecha o quinto segmento e o discurso do Presidente.

\section{Sujeitos, objetos e destinadores destacados do discurso para a análise}

$$
\begin{aligned}
& \mathrm{S}=\text { sujeito } \\
& \mathrm{S} 1=\text { Sarney } \\
& \mathrm{S} 2=\text { brasileiros } \\
& \mathrm{S} 3=\mathrm{S} 1+\mathrm{S} 2 \\
& \mathrm{~S} 4=\text { Brasil } \\
& \mathrm{S} 5=\text { partidos (inclusive a Aliança Democrática) } \\
& \mathrm{S} 6=\text { auxiliares de governo }
\end{aligned}
$$

\footnotetext{
8 Destaque nosso.
} 
$\underline{\mathrm{S} 7}=$ poder civil

$\mathrm{S} 7=$ poder militar

$\mathrm{St}=$ todos os setores da sociedade brasileira

$\mathrm{Ov}=$ objeto de valor (objeto-valor)

Ov1 = qualidades de cidadão

Ov2 = qualidades de chefe da nação

Ov3 = solução problemas graves, solução da crise

$\overline{\mathrm{Ov} 3}=$ problemas graves, crise

Ov4 = governo de mudanças

Ov $5=$ mudanças

Ov6 = definição duração mandato presidencial (mandato definido)

$\overline{\mathrm{Ov} 6}=$ indefinição do mandato

Ov $6^{\prime}=$ mandato de 6 anos

Ov6" = mandato de 5 anos

Ov6"' = redução de um ano de mandato

Ov7 = exame do assunto (sobre mandato), discussão, negociação

$\overline{\mathrm{Ov} 7}=$ fim discussão assunto

Ov8 = mobilidade

$\overline{\mathrm{Ov} 8}=$ imobilidade

Ov9 $=$ entendimento político

Ov10 = contenção da corrida inflacionária, da carestia e da recessão

Ov11 = condições para se governar (governabilidade)

Ov12 $=$ consolidação processo democrático

$\overline{\mathrm{Ov} 12}=$ consolidação processo anti-democrático

Ovt $=$ objeto de valor total $=$ sociedade justa que atenda aos anseios de toda a população

Ov13 = regime governamental

Ov13' = regime presidencialista

${\overline{\mathrm{Ov}} 13^{\prime}}^{\prime}=$ regime parlamentar

Ov14 = eleições diretas

$\overline{\mathrm{Ov}}^{\prime}{ }^{\prime}=$ impossibilidade de escolher o governo por eleições diretas

$\overline{\mathrm{Ov} 15}=$ causa de problemas

Ov16 = luta contra as dificuldades

$\mathrm{D}=$ Destinador (com letra maiúscula)

D1 = sociedade enquanto instituições pelas quais S1 passou

D2 = destino 


$$
\begin{aligned}
& \mathrm{D} 3=\mathrm{S} 1 \\
& \mathrm{D} 4=\text { lei } \\
& \mathrm{D} 5=\text { conjuntura mundial } \\
& \mathrm{D} 6=\text { Deus } \\
& \mathrm{PN}=\text { programa narrativo } \\
& \mathrm{F}=\text { enunciado de fazer }
\end{aligned}
$$

\section{SEGMENTO 1}

Relato de apresentação: assim se pode caracterizar o primeiro segmento do discurso do Presidente. Nele, Sarney (S1) instaura-se como sujeito mínimo; modaliza-se e adquire competência para realizar sua performance.

Inicia seu pronunciamento fazendo uso da primeira pessoa do singular ("Estou aqui...") e essa é a tônica de todo o primeiro segmento. No terceiro parágrafo, utiliza uma embreagem, onde "Brasil" aparece como sujeito cognitivo, sendo que o objeto de seu SABER é o próprio S1. Depreendese, então, uma narrativa anterior, na qual Brasil já tinha realizado uma performance que lhe deu esse SABER. Com esse procedimento, S1 procura estabelecer um contrato fiduciário, um comprometimento entre "Brasil" ("Brasileiras e brasileiros") e ele. Esse sincretismo serve aos propósitos de manipulação de S1, que deseja o aval de "brasileiras e brasileiros", no que tange à sua modalização.

A modalização de S1 dá-se em eixos diferentes. Paradigmaticamente, S1 é cidadão e Presidente, modalizando-se ora como um ora como outro. Sintagmaticamente, o ontem, o hoje e o amanhã corroboram essa modalização, por meio das embreagens e debreagens espaço-temporais (situando os fatos reveladores das características pessoais e/ou políticas de S1).

"Por formação e experiência..." evidencia um actante coletivo de uma narrativa anterior, subjacente: a sociedade, enquanto conjunto de instituições pelas quais S1 passou (primeiro Destinador que S1 apresenta como formador de seu caráter): 


\section{D1}

(S1 $\cap$ Ov1), onde Ov1 = qualidades de cidadão

"Experiência" apresenta S1 como realizador de performances vitoriosas no passado. Conjuntamente, "formação e experiência" acrescentam-lhe o SABER FAZER e o SABER SER (como em "sou prudente").

S1 é cidadão e possui uma série de atributos positivos que, somados aos de chefe de nação, farão dele um homem de Estado com competência para cumprir suas obrigações e tomar decisões importantes. Isso lhe garantirá um PODER FAZER.

"A responsabilidade que o destino me colocou à frente é minha e dela não vou fugir". Aqui S1 adquire a competência de Presidente de um D2 ("Destino"):

D2

(S1 $\cap$ Ov2), onde Ov2 = qualidades de chefe da nação.

Tem um DEVER FAZER e um QUERER cumprir seu DEVER. A autoridade de chefe de nação lhe dá também o PODER FAZER SER, dentro dos limites do contrato social e político estabelecido pelo cargo.

S1 refere-se ao pronunciamento feito em 22 de julho de 1985. Com a data vem a afirmação: "Quem esperava um Presidente autoritário soube, logo de início, que esse Presidente não seria eu”. Essas referências espaçotemporais provam que a modalização não se faz apenas no momento presente. Ao contrário, ela é um processo que se iniciou no passado e percorre o presente. Mais ainda, é projetada para o futuro, quando S1 afirma: "acerto e posso cometer equívocos". Ou seja, se, no futuro, S1 fizer algo que o Brasil considere errado, esse erro poderá ser assumido potencialmente sem grandes prejuízos políticos, pois já havia sido previsto e a nação alertada para a possibilidade. "Logo de início" autoriza S1 a utilizar-se virtualmente 
do "nunca", ou seja, desde o início de seu mandato ficou claro que ele nunca seria autoritário.

"Nesta noite, eu quero acrescentar: quando me convenço de que estou no caminho certo, eu dele não me afasto, quaisquer que sejam as dificuldades, conseqüências ou lutas". A debreagem temporal traz consigo dois fatores importantes. O primeiro é o acréscimo de mais uma característica da personalidade de S1: seu caráter dinâmico. Ele é capaz de persuadir a si próprio, a partir de uma auto-sanção, ou seja, além de sujeito-Destinatário, investe-se também do papel de Destinador-julgador. O segundo fator a se considerar é o estabelecimento de oponentes: dificuldades, conseqüências, lutas.

Os anti-sujeitos, num "crescendo", tornam-se um pouco mais declarados em: "Não me tem faltado para isso espírito de tolerância, considerado muitas vezes até excessivo por muitas pessoas". "Muitas pessoas", embora mais materializados, são ainda anti-sujeitos indefinidos. Mesmo assim, evidenciam uma intimidação insinuada por S1.

"Não me tem faltado espírito de tolerância (...)" deixa a impressão de "boa-vontade" de S1 para com todos com quem tem de lidar no exercício de seu governo. Além disso, fazendo-se uma análise sêmica em nível frástico (modelo de Pottier), encontramos o lexema "tolerar", elemento eufórico9 que torna S1, que tolera, superior em relação aos tolerados e à comunidade política. Por outro lado, um governo democrático não depende da "tolerância" de um Presidente, caso contrário não estaria vivendo sob Estado de Direito. A afirmação da tolerância de S1, acompanhada da que a antecede ("sem abdicar da autoridade de chefe da nação, exerço um governo democrático e aberto"), autoriza um discurso subjacente: a democracia é fruto da tolerância de S1. Dentro de uma perspectiva democrática, o Presidente pode acatar a vontade da nação, sem que isso implique perda de autoridade. No entanto, usa a tolerância, um atributo de poder paternalista e autoritário. Desse modo, autoridade e autoritarismo se confundem.

Sendo assim, dois discursos correm paralelamente dentro de um conceito duvidoso de democracia: o de coronel e o de super-herói. O coronel,

9 Em um quadrado semiótico, euforia (elemento eufórico) é o termo positivo que valoriza os microuniversos semânticos. Opõem-se à disf 
figura típica da realidade política brasileira, exerce o poder de Destinadormanipulador (atribui a si a competência por meio da intimidação e da força bruta) e de Destinador-julgador (ele próprio sanciona sua performance). Seu discurso é autoritário e o bem e o mal ficam à mercê de sua boa vontade. O super-herói é o guardião da democracia, de seu ponto de vista e de seus aliados.

Em suma, o segmento todo se caracteriza como um relato de apresentação, onde S1 se modaliza e se instaura como sujeito do QUERER, do DEVER FAZER e potencialmente do PODER FAZER SER. Para essa modalização, corroboram as embreagens e debreagens espaço-temporais que dão a perspectiva de um processo em curso, sendo o presente apenas um momento desse percurso. Anti-sujeitos se apresentam de modo indefinido e potencial, e é por esse meio que a intimidação, dentro do processo manipulatório, começa a se apresentar.

\section{SEGMENTO 2}

"Franqueza" retoma o conteúdo do primeiro segmento, onde se inicia a modalização de S1: é o procedimento anafórico que assegura o encadeamento entre este segmento e o anterior.

"Devo admitir que nós vivemos uma fase de múltiplas, acentuadas e grandes dificuldades". Com estas palavras S1 estabelece-se como sujeito cognitivo. Possui um SABER concreto a respeito da situação do país que o autoriza a apresentar suas conclusões e propostas de solução dos problemas. Sendo assim, S1 $\cap$ PN (a busca da definição da duração do mandato presidencial, uma vez que se modalizou suficientemente para realizar sua performance. Possui um QUERER, um DEVER e um PODER FAZER SER (inferido da autoridade do cargo de chefe da nação). Além disso, tem um SABER, porque conhece o passado e sabe o que deve ser feito, no futuro próximo, para que se saia da crise.

Em seu percurso narrativo, S1 instaura um novo sujeito. Transforma "brasileiras e brasileiros" no sujeito (S2), atribuindo-lhe um QUERER e

um FAZER. Entra em sincretismo com S2 e, assim, estabelece ainda outro sujeito (S3 = S1 + S2). Em "Queríamos e lutamos por um governo de 
mudanças. E o Brasil mudou" e "Para resolver os problemas ... devemos ter a solução adequada ao primeiro deles ...", S1 utiliza-se de embreagens temporal e de enunciador e desenvolve dois programas narrativos auxiliares paralelos, vinculados ao programa da busca da definição da duração do mandato, com os quais exerce um fazer manipulatório.

No primeiro programa auxiliar, essas embreagens apresentam S1 e S2 unidos no passado, lutando por um mesmo Ov (Ov4 = governo de mudanças). Segundo S1, S3 transformou seu QUERER em realidade, ou seja, $\mathrm{F}[\mathrm{S} 3 \rightarrow(\mathrm{S} 3 \cap \mathrm{Ov} 4]$ é um $\mathrm{PN}$ atualizado no passado e realizado com sucesso no presente.

S3 queria e lutou por um governo de mudanças, ou seja, um governo que fizesse o Brasil mudar. Ora, S1 é o governo, portanto, o enunciado implícito é F [S1 $\rightarrow(\mathrm{S} 4 \cap$ Ov5)]. Melhor explicando, foi S1 que fez o Brasil (S4) entrar em conjunção com mudanças (Ov5). O que se verifica, então, é que S1 FAZ S2 CRER que ele, S2, transformou diretamente o Brasil quando, na verdade, conseguiu apenas a mudança do antigo governo para um novo governo.

Esse primeiro programa auxiliar constitui-se em um FAZER CRER difícil de ser sustentado, porque logo a seguir admite-se que "vivemos uma fase de múltiplas, acentuadas e grandes dificuldades". Portanto, a situação atual do Brasil é a de crise ( $\mathrm{S} 4 \cap \overline{\mathrm{Ov} 3})$ e a responsabilidade é de S1, o real sujeito da ação governamental. Entretanto, S1 FAZ S2 CRER que a responsabilidade pela "mudança" é de S + S2, comprometendo assim este último. O PN no presente é, conseqüentemente, um PN de fracasso e não de sucesso, como se quer fazer crer. A saída que S1 encontra para que seu governo não caia no descrédito e para que S2 não desanime é, em primeiro lugar, identificar crise com mudança e, em seguida, apresentar uma proposta de programas narrativos a serem realizados, para que se saia da crise.

No segundo programa auxiliar, o enunciador investe-se do papel de Destinador (D3) e atribui competência (faz SABER e DEVER quanto à solução dos problemas do país) ao Destinatário-sujeito S2. Com isso, S1 deseja que a performance de S2 seja a de colaborar para a solução dos problemas com base na ótica do enunciador-Sarney. Isto é, que S2 assuma como Ov a definição da duração do mandato presidencial (Ov6), colocando-se como necessariamente anterior à conquista de um outro $\mathrm{Ov}$ 
(Ov3 = solução dos problemas do país). Sendo assim, o PN que tem Ov6 como objeto de valor é um PN de uso em relação ao que tem Ov3 como objeto de valor. Este último $\mathrm{PN}$, de base, é o principal da narrativa em curso.

Neste segundo programa auxiliar, sob o pretexto de solucionar os problemas do país, o enunciador utiliza-se de um FAZER QUERER quanto à definição da duração de seu mandato.

Desse modo, com esses dois programas auxiliares paralelos, o enunciador S1 busca, com base no "sucesso" do primeio programa, persuadir S2 de que a "repetição" da aliança S1 + S2 tornará possível um "novo sucesso". É um FAZER CRER indispensável à viabilidade de um FAZER QUERER a solução proposta (Ov6) e FAZER FAZER o que for necessário à sua efetivação. A fusão desses dois programas auxiliares gera o enunciado:

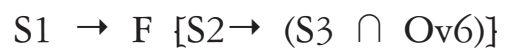

posição

inicial de S2 (d)

(b)

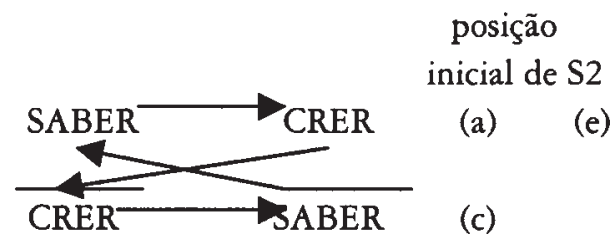

(a)

(e)

Pode-se resumir e compreender melhor o exposto no segundo segmento até o momento por meio do quadrado semiótico, onde as setas indicam o percurso de S2 e o que S1 deseja fazer com que S2 faça:

(a) S2 acreditava que mudanças acabariam com os problemas ("O Brasil mudou"); (b) passou a não crer, pois, segundo $\mathrm{S} 1$, houve mudanças, mas problemas não acabaram ("vivemos uma fase de ... grandes dificuldades");

(c) S2 passou a não saber o que fazer para sair da crise;

(d) S1 faz com que S2 saiba: "Para resolver os problemas ... a duração do mandato presidencial";

(e) com o SABER, S2 poderá CRER que se fizer como S1 diz os problemas se solucionarão. 
Mais do que um FAZER QUERER (a definição da duração do mandato), o enunciado acima representa a permanência de S1 no poder como chefe de nação, na condução do governo de transição, apesar do fracasso não assumido. A articulação desses dois programas auxiliares equivale, portanto, à formulação de um contrato para o qual S1 busca a adesão de S2 (um fazer interpretativo): trata-se da persuasão calcada num SABER.

"Convoquei os partidos para conjuntamente examinarmos o assunto, fora dos interesses pessoais, de candidaturas de grupos, de facções e de ambições, vendo o problema em função do interesse nacional". A debreagem de enunciador permite a S1 fazer uma embreagem temporal, remetendo a narrativa para o passado, onde se verifica que:

$\mathrm{F}[\mathrm{S} 1 \rightarrow((\mathrm{S} 1+\mathrm{S} 5) \cap \mathrm{Ov} 7)]$

Aqui S1 fez os partidos (S5) e ele próprio passarem ao exame do assunto (Ov7), correspondente à definição da duração do mandato. Esta passagem define identificações e oposições importantes como:

\begin{tabular}{l|l|l}
\hline Ov & $x$ & $\overline{\text { Ov }}$ \\
\hline definição & & indefinição \\
\hline interesse nacional & & $\begin{array}{l}\text { interesses pessoais, de candidaturas de } \\
\text { grupos, de facções, ambições etc }\end{array}$ \\
\hline
\end{tabular}

"Interesses pessoais, de candidaturas de grupos, de facções, ambições" tem caráter disfórico e insinuam um QUERER FAZER. Sendo assim, com a definição de anti-objetos, anti-sujeitos podem ser depreendidos, embora S1 não os determine nominalmente. São apenas insinuados por S1, a partir das oposições estabelecidas como mecanismos de seu processo manipulatório.

Esses mesmos Ov e $\overline{\mathrm{Ov}}$ expressam as regras sobre as quais S1 deseja examinar o assunto. Isto é, a discussão que S1 deseja tem suas condições previamente estabelecidas. Aqui as embreagens e debreagens de enunciador são muito importantes: 


$$
\begin{aligned}
& \text { "convoquei” = eu, chama à discussão; - agente promotor da democracia; } \\
& \text { "examinarmos" = nós, discussão; - democracia; } \\
& \text { "espero" = eu, aguarda; - não participação na discussão. }
\end{aligned}
$$

Portanto, S1 = agente da democracia; S5 discute, mas não define. Indefinição é o anti-objeto de valor que impede que $\mathrm{S} 3$ possa deixar de ter problemas. Conseqüentemente, $\mathrm{S} 1=$ defensor do interesse nacional e $\mathrm{S} 5$ = os que não deixam o país sair da crise. A afirmação de S1 atinge diretamente os partidos, mas S1 a ameniza: "Compreendo as dificuldades dos nossos líderes". Desse modo, apresenta atenuantes à performance dos líderes ("dificuldades") e se utiliza da embreagem de enunciador para aparecer como também subordinado aos líderes ("nossos"). S1 se apresenta como cognitivo e complacente ("compreendo"). Infantiliza as relações, aparecendo como o pai que tudo sabe, que ensina a seus filhos e compreende que estes não consigam realizar suas performances adequadamente.

"Contudo, cheguei à conclusão de que a nação não pode ficar imobilizada na perplexidade desse embate. Porque, acima da Aliança Democrática, acima dos partidos, está o interesse do Brasil, que eu jurei defender": $\mathrm{F}[\mathrm{S} 5 \rightarrow(\mathrm{S} 4 \cap \overline{\mathrm{Ov} 8})]$. S1 acrescenta uma oposição à seqüência delas estabelecidas ainda neste segmento: imobilidade (Ov8) x mobilidade (Ov8). Há que se notar aqui que a relação entre S1 e a Aliança Democrática mudou. No parágrafo 11 (primeiro segmento), S1 havia entregado a coordenação política de seu governo à Aliança Democrática, o que colocava esta última como adjuvante de S1. Todavia, o que se verificava neste segmento é que de adjuvante ela passa a anti-sujeito (incluída em S5), que se opõe a S1 e a S2.

Nos próximos dois parágrafos, S1 evoca um Destinador (D4 = Lei), que dá competência a todos os detentores de mandato - inclusive a ele e a Tancredo Neves - para ficar seis anos no poder (Ov6'). Assim, tem-se:

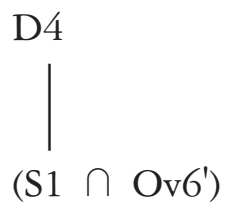


Ainda outras oposições são apresentadas como correspondentes à grande oposição definição x indefinição:

\begin{tabular}{l|l|l}
\hline Ov & $\mathrm{x}$ & $\overline{\mathrm{Ov}}$ \\
\hline & & $\begin{array}{l}\text { solapamento da hierarquia e do } \\
\text { serviço público }\end{array}$ \\
\hline $\begin{array}{l}\text { dificuldade de formulação } \\
\text { da política interna }\end{array}$ \\
\hline externos do Brasil & & \\
\hline
\end{tabular}

Ao final do segundo segmento do discurso, o enunciador declara a existência de mais um anti-sujeito, apresentado de forma indeterminada ("a indefinição que se procurou criar..."). Utilizando-se da voz ativa com sujeito indeterminado, logo após ter apresentado S5 (partidos, incluindo a Aliança Democrática), S1 deixa subentendido que S5 tem intenção de manter a duração do mandato sem definição, o que impede que $\mathrm{S} 3$ solucione os seus problemas. A apresentação de anti-sujeitos instaura um confronto expresso pelos seguintes enunciados:

$$
\mathrm{S} \rightarrow(\mathrm{S} 3 \cap \mathrm{Ov} 6) \leftrightarrow \mathrm{F} \overline{[\mathrm{S}} \rightarrow(\mathrm{S} 3 \cap \overline{\mathrm{Ov} 6})] \text {; onde } \overline{\mathrm{S}}=\mathrm{S} 5 .
$$

Por outro lado, a embreagem temporal para o passado (“...que se procurou criar") permite ao enunciador FAZER CRER que esse anti-sujeito não mais existe, concluindo-se que S1 teria sido vitorioso nesse confronto e que o discurso que profere seria a expressão de sua vitória.

Por fim, "a indefinição que se arrasta" traz consigo a indicação do processo em curso, o que, somado aos cinco meses que o Presidente espera, confirma a tese de que o discurso do Presidente não é nem um começo nem um fim, mas parte de um processo.

Resumindo, o segundo segmento apresenta como programa narrativo principal aquele que visa à solução dos problemas e que tem como progra- 
ma de uso a definição do mandato presidencial. S1 cria oposições de objetos de valor, relacionados a Ov6 e Ov6. Com base em Ov6, S1 identifica anti-sujeitos e anti-objetos. S1 coloca-se ao lado da definição, que traz consigo a defesa dos interesses do Brasil. Os demais (anti-sujeitos e antiobjetos) apresentam-se como inimigos desses interesses. O jogo da ilusão e da intimidação faz parte do processo de manipulação com o qual S1 objetiva estabelecer um contrato de cumplicidade com S2, persuadindo-o a aderir à sua proposta.

\section{SEGMENTO 3}

Na passagem do segundo para o terceiro segmento, repete-se o procedimento anafórico, com "falar claramente sobre esse assunto", referindo-se "esse" à apresentação do tema, feita no segmento anterior. Intervém ainda na segmentação do texto um elemento disjuntivo: a recorrência de "Brasileiras e brasileiros".

No segmento anterior, S1 lutava para conseguir a definição do mandato presidencial, apresentando-a como condição sine qua non para a solução de todos os problemas pelos quais o Brasil passa. Nesse sentido, evocou um Destinador legal (D4 = Lei) que, em sua opinião, garantiu a ele e a Tancredo Neves - quando da sua eleição - um mandato de seis anos. Esse dispositivo é reforçado no terceiro segmento, quando afirma: "até lá, no entanto, exercerei plenamente o mandato que me foi confiado, que jurei defender na forma da Constituição e que consta de um diploma expedido pelo Congresso Nacional”.

Todavia, S1, contrariando a Constituição, define a duração de seu mandato em cinco anos e, para isso, utiliza-se de um PN auxiliar: $\mathrm{F}\left[\mathrm{S} 1 \rightarrow\left(\mathrm{S} 1 \cap \mathrm{Ov} 6^{\prime \prime}\right)\right] \rightarrow \mathrm{F}[\mathrm{S} 1 \rightarrow(\mathrm{S} 1 \cap \mathrm{Ov} 6 ")]$.

Em outras palavras, S1 FAZ SABER que renunciará a um ano de seu mandato (Ov6"') e que, conseqüentemente, ficará no poder por cinco anos (Ov6").

A atitude de renunciar a alguma coisa em função de um bem futuro ou de provar a desambição é um elemento euforizante que procura mani- 
pular os valores sociocultrais brasileiros, uma vez que a não-ambição é tida, de modo generalizado no Brasil, como um valor moral e ético positivo. O recurso manipulatório usado pelo enunciador apóia-se, portanto, na sobremodalização do discurso burocrático pelo discurso moral/ético.

Sua determinação é firme e o leva a ordenar a seus auxiliares (S6) o fim do exame do assunto $(\overline{\mathrm{Ov} 7})$. Assim, $\mathrm{F}[\mathrm{S} 1 \rightarrow(\mathrm{S} 6 \cap \overline{\mathrm{Ov} 7})]$.

Para justificar sua atitude, modaliza seu ato. Nesse sentido, projeta planos de trabalho para o futuro, em sincretismo com S2, em cuja tarefa colaboram muito as embreagens espaço-temporais e de enunciador: "Acresce ainda que 1988 será o ano de adaptações das Constituições estaduais; da elaboração das leis eleitorais, das leis partidárias, das leis complementares, e revisão de toda a legislação ordinária, determinadas pela nova Constituição, além das eleições municipais que teremos de realizar". "No ano seguinte, 1989, comemoraremos o centenário da fundação da República, e comemoraremos esse centenário com a eleição que eu presidirei, de meu sucessor".

A modalização de seu ato também se dá pelo mecanismo das oposições, em relação ao Ov e seu contrário $(\overline{\mathrm{Ov}})$, onde Ov é o mandato de cinco anos. Assim, verificam-se as relações abaixo:

\begin{tabular}{l|l|l}
\hline Ov & $\mathrm{x}$ & $\overline{\mathrm{Ov}}$ \\
\hline cinco anos & & quatro anos \\
\hline $\begin{array}{l}\text { amplo entendimento, } \\
\text { conciliação; }\end{array}$ & & \\
\hline saída da crise & & \\
\hline desambição & & prejuízos à transição democrática \\
\hline & & $\begin{array}{l}\text { prejuízos aos trabalhos da Assembléia } \\
\text { Nacional Constituinte }\end{array}$ \\
\hline & & prejuízos ao país \\
\hline
\end{tabular}

Aqui também a embreagem de enunciador procura estabelecer contrato com S2, no sentido de FAZÊ-lo NÃO FAZER. Ou seja, de persuadilo a não aderir à proposta de quatro anos de mandato presidencial. Para isso, tenta FAZER S2 CRER que a adoção dessa duração de mandato acar- 
reta resultados negativos e, assim, procura FAZER S2 NÃO QUERER essa proposta. Mais uma vez observa-se a intimidação como um mecanismo utilizado por S1 dentro do processo manipulatório.

Para poder tomar a decisão da definição do mandato presidencial, S1 precisa se investir do papel de Destinador, Destinador este superior à Assembléia Constituinte, superior à Constituição e, conseqüentemente, à própria sociedade brasileira. Assim, S1, enquanto D3, opõe-se ao enunciado de estado que se apresentou no segmento anterior, no qual:

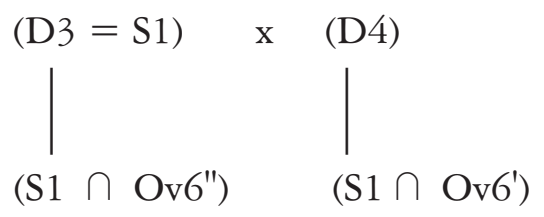

É como Destinador-manipulador que S1 atribui a si competência para definir o mandato e é como Destinador-julgador que se auto-sanciona positivamente ao modalizar seu ato. Agindo assim, subverte a lei maior que o fez Presidente, tornando-se anti-Destinador, que se confunde com antisujeito no plano da imanência.

Seu discurso é autoritário, não polêmico, pois rompe a negociação unilateralmente, sobrepondo seu QUERER a qualquer outro. Esse discurso se opõe ao anterior e inicial, que se caracterizava pela ponderação e democracia. No entanto, seu investimento como Destinador é fraco e S1 não pode permanecer por muito tempo no pretenso plano da transcendência, pois, como Presidente da República tem apenas os poderes concernentes ao Executivo. Seu discurso é facilmente desmontado e a real situação rapidamente detectada, como se pode verificar pelo quadrado semiótico:

(a)

(c)

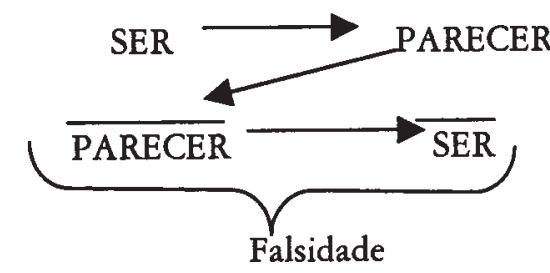

(b)

(d) $\}$ Mentira 
(a) S1 é competente (tem poder) para ficar seis anos no governo;

(b) S1 parece competente (parece ter poder) para abrir mão de um ano de seu mandato e defini-lo em cinco anos;

(c) S1 deixa de parecer competente (deixa de parecer ter poder) para definir seu mandato em cinco anos, pois ele mesmo diz que jurou defender a Constituição e esta define o mandato presidencial em seis anos;

(d) Evidencia-se que S1 não é competente (não tem poder) para definir seu mandato, pois é do Executivo e não do Legislativo.

Portanto, o que se verifica é a Mentira de sua competência e, conseqüentemente, a Falsidade de suas afirmações.

Seu discurso não polêmico é o discurso do fracasso no plano do SER. Dá-se no plano do PARECER, o que o torna fraco ao ponto de fazê-lo solicitar SANÇÃO positiva a seu ato e trazê-lo novamente ao plano da imanência, forçando-o a reabrir negociações:

"Dos partidos políticos eu espero solidariedade".

"Aos governadores dos Estados, aos Deputados e Senadores constituintes peço apoio e compreensão".

A negociação vai mais adiante e S1 propõe entendimento político (Ov9) a todos os setores da sociedade brasileira (St), um sincretismo total, união total entre $\mathrm{S} 1$ e a sociedade em geral (trabalhadores, empresários, todos os partidos no Congresso): "Se não formos capazes de chegar a um acordo sobre as bases mínimas para um entendimento político, nós não teremos a menor possibilidade de conduzir um esforço efetivo para deter a carestia e retomar o desenvolvimento econômico. Contra a inflação é necessária a união de todos. É necessária a união firme de todos nós". Assim, S1 $\rightarrow$ (St $\cap$ Ov9). Ressalte-se que S1 considera como bases para um acordo a já definida duração do mandato presidencial em cinco anos. Ou seja, Ov9 = Ov6".

$\mathrm{Na}$ negociação, $\mathrm{S} 1$ apresenta novo Ov que se define por oposição ao seu contrário $(\overrightarrow{\mathrm{Ov}})$. Ou seja, apresenta a necessidade de entendimento político como condição básica para a contenção da corrida inflacionária, da carestia e da recessão (Ov10). Desse modo, o PN que possui Ov10 como Ov passa a ser de base e o mandato, PN de uso. Mais ainda, S1 acrescenta novos elementos que tocam diretamente ao processo de redemocratização do país. Apresenta o poder civil (S7) e a necessidade de condições para se governar, a governabilidade (Ov11). 
Nesse sentido, S1 monta uma seqüência de PN, onde poder civil (S7) e governabilidade (Ov11), contenção da carestia, da inflação e da recessão (Ov10) e a definição do mandato (Ov6) encadeiam-se e se posicionam como PN de uso em relação a um Ov maior, que é a consolidação do processo democrático (Ov12), o que levará a uma sociedade justa, que atenda aos anseios de toda a população (Ot). Atentando-se para as afirmações:

"Para que o processo democrático possa se consolidar, é essencial demonstrar que o poder civil tem condições de governar";

"A governabilidade do poder civil depende, porém, de uma inalterável definição do prazo que estabelece a periodicidade do mandato";

"Não estamos sob nenhuma ameaça ao processo democrático. Mas devemos nos antecipar a qualquer deterioração da situação nacional" pode-se depreender a intimidação por meio das oposições:

\begin{tabular}{l|c|l}
\hline poder civil (S7) & $\mathrm{x}$ & poder militar $\overline{(\mathrm{S} 7)}$ \\
\hline $\begin{array}{l}\text { não estamos sob } \\
\text { nenhuma ameaça }\end{array}$ & $\mathrm{x}$ & estamos sob ameaça \\
\hline processo democrático (Ov12) & $\mathrm{x}$ & proc. anti-democrático $(\overline{\mathrm{Ov} 12})$ \\
\hline
\end{tabular}

Se é necessário "demonstrar que o poder civil tem condições de governar, deve haver algum Destinador-julgador em oposição ao poder civil (anti-Destinador-julgador). Se há um Destinador-julgador há, por oposição, um Destinador-manipulador (ou seja, um anti-Destinadormanipulador). Desse modo, S1 vai criando o percurso de um anti-sujeito que se opõe ao projeto de Ovt. Utiliza-se de mecanismos de persuasão para que S2 adira à sua proposta, estabelecendo um contrato. Associado a isso, S1 novamente se investe do papel de Destinador da sociedade brasileira, fazendo-a saber como sair da crise e alcançar seu Ovt. Para isso, apresenta um projeto de narrativa a ser feito por S2 em conjunto com S1.

A seqüência de PN apresentada por S1 pode ser assim expressa: 


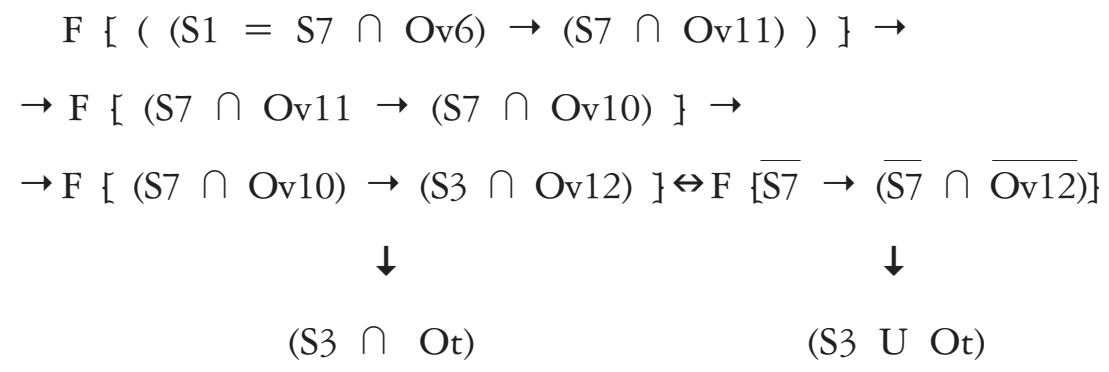

De acordo com o exposto, S1caracteriza-se como um "salvador da Pátria", o único capaz de manter o equilíbrio e a estabilidade econômica e política do país. Contudo, ao afirmar: "A governabilidade do poder civil depende, porém, de uma inalterável definição do prazo que estabelece a periodicidade do mandato", S1 utiliza-se do adjetivo "inalterável” como atributo indispensável à definição do mandato, para que a governabilidade possa existir. Sendo assim, temos:

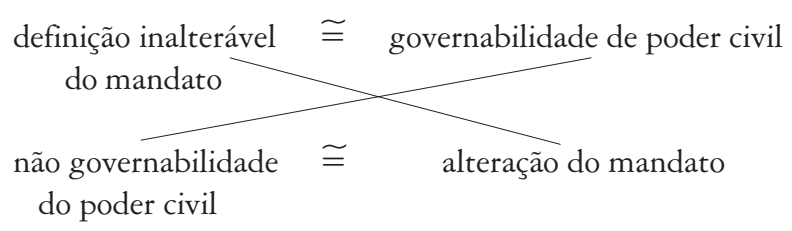

No entanto, se S1 alterou ou quis alterar o mandato, ele mesmo acaba por colocar-se como anti-sujeito do poder civil.

Trabalhando ainda as oposições, S1 acrescenta aos dados já contrapostos outros elementos, como podemos ver pelas afirmações abaixo:

Todos os partidos, no Congresso Nacional, devem desempenhar uma importante tarefa e prestar um grande trabalho ao país, mobilizando-se para esta causa. O que proponho, assim, não é um pacto político de apoio ao governo. Eu proponho uma agenda ampla, social e política de transição democrática, uma co-responsabilidade com o Executivo, para a superação dos problemas de consolidação do nosso processo democrático. Sei, com grande pesar, que o povo está passando por sérias e por grandes dificuldades. Os Estados encontram-se em situação difícil. Os Governadores lutam contra uma situação financeira de anarquia. Eles precisam de tempo, eles precisam de tempo para trabalhar. As greves neste instante prejudicam os interesses dos próprios trabalhadores e dos funcionários públicos. 
De modo resumido, o conjunto desses elementos pode ser visualizado no quadro abaixo:

\begin{tabular}{l|l|l}
\hline Ov & $x$ & $\overline{O v}$ \\
\hline definição & & indefinição \\
\hline governabilidade & & \\
\hline & & paralisia \\
\hline entendimento & & \\
\hline & & inflação, recessão, carestia \\
\hline & & deterioração da situação nacional \\
\hline & & greves \\
\hline
\end{tabular}

Pelo elemento "greves", novos sujeitos e anti-sujeitos passam a se opor:

\begin{tabular}{l|l|l}
\hline $\mathrm{S}$ & $\mathrm{x}$ & $\mathrm{S}$ \\
\hline S1 (Executivo nacional) & & \\
\hline $\begin{array}{l}\text { todos os partidos políticos } \\
\text { estaduais) }\end{array}$ & & \\
\hline & & $\begin{array}{l}\text { trabalhadores e funcionários } \\
\text { públicos em greve }\end{array}$ \\
\hline
\end{tabular}

Há que se notar que alguns Ov se equivalem ou se pressupõem na visão de S1: Ov6 $\cong$ Ov6" $\cong$ Ov9 $\cong$ união de todos na luta contra a carestia e recessão. Assim, a negociação que S1 propõe é totalmente calcada em regras pré-estabelecidas por S1. Ou seja, não é aberta e pressupõe a aceitação de sua proposta de mandato de cinco anos. Desse modo, a afirmação de S1: "o que proponho, assim, não é um pacto político de apoio ao governo" vair por terra, pois o que se evidencia é exatamente o seu oposto. A esse respeito, é importante ressaltar que S1 procura, no plano do PARECER, colocar-se como o defensor do interesse de todos os setores da sociedade e, por conseguinte, de toda a nação. Todavia, o que se oberva é que S1 opõe dois grandes grupos: de um lado, o Executivo nacional, os governadores dos Estados e os partidos políticos presentes no Congresso Nacional; de outro lado, os trabalhadores e funcionários públicos em greve. Es- 
tes últimos são, então, colocados na situação de anti-sujeitos; porém, como já se mostrou, ao subverter a Lei Maior do país, é S1 que se caracteriza, de fato, como um anti-sujeito/anti-Destinador.

Em suma, o terceiro segmento é o espaço político onde se dá a tentativa de estabelecimento de acordo sobre a definição da duração de mandato presidencial entre $\mathrm{S} 1$ e os vários setores da sociedade brasileira. Para atingir tal objetivo, S1 utiliza-se de vários recursos:

a. investe-se de Destinador ao decidir a duração do mandato, porém, com esse mecanismo torna-se anti-Destinador, anti-sujeito da sociedade brasileira. Além de não conseguir seu intuito, pois não tem competência para arvorar-se Destinador maior da sociedade brasileira, é obrigado a reabrir negociações;

b. recorre a mecanismos de intimidação, procurando persuadir S2 a aderir à sua proposta;

c. investe-se novamente do papel de Destinador, ao apresentar a S2 projeto de programa a ser cumprido para se atingir Ovt. O projeto apresentado por S1 é composto de PN encadeados e pressupostos, onde a definição da duração do mandato presidencial é condição básica para a solução dos problemas econômicos e a solução destes é a condição prévia para a consolidação do processo democrático que levará a uma sociedade mais justa.

O entendimento, no entanto, só pode se dar sobre acordo mínimo, que é o mandato de cinco anos. Portanto, toda negociação de S1 equivale a uma proposta de pacto político de apoio a seu governo e à sua permanência por mais um ano no poder.

\section{SEGMENTO 4}

O mesmo sujeito-enunciador, S1, apresenta-se neste segmento diante do mesmo sujeito-enunciatário, S2. Todavia sua modalização dá-se de modo diferente. Aqui não mais se apresenta como Presidente, mas tão somente como cidadão. Não se investe de um DEVER, mas apenas de um QUERER FAZER SABER. 
O Ov em questão também não é mais o mandato ou a contenção da inflação e carestia. É agora a definição do regime governamental (Ov13). S1 tem uma proposta: "regime presidencialista com participação forte do Congresso nas tarefas do governo" (Ov13') e opõe-no ao regime parlamentarista $\left(\overline{\mathrm{Ov} 13} 3^{\prime}\right)$. Então, $\left(\mathrm{S} 1 \cap \mathrm{Ov} 13^{\prime}\right)$. "Depois de ter optado pelas eleições diretas(( incluídas hoje na Constituição por mensagem de minha iniciativa ( o povo brasileiro dificilmente aceitaria que lhe retirassem o poder de constituir o seu governo". Argumenta favoravelmente a Ov13', utilizando-se do mecanismo de oposições, onde alinha Ov13' ao poder de S2 constituir seu governo, identificando-se com eleições diretas (Ov14). Assim, S1 organiza uma seqüência de equivalências, na qual:

\section{Ov13' $\cong$ Ov14 $\cong$ PODER FAZER SER}

e, por oposição, esta seqüência tem como $\overline{\mathrm{Ov}}$ :

\section{$\overline{\mathrm{Ov} 13^{\prime}} \cong \overline{\mathrm{Ov} 14} \cong \mathrm{NÃO}$ PODER FAZER SER.}

Com estas palavras, S1 cria anti-sujeitos potenciais, indefinidos, que fariam S2 entrar em relação de despossessão com o poder de constituir seu governo. Dessa forma, S1 QUER FAZER S2 CRER que somente em conjunção com Ov13' estará investido do PODER FAZER SER politicamente. A opção pelo regime parlamentar $\left(\overline{\mathrm{Ov} 13^{\prime}}\right)$ permite que anti-sujeitos roubem o poder de $\mathrm{S} 2$ escolher seu governo por meio de eleições diretas. Tenta, pois, FAZER S2 FAZER a defesa de sua proposta. Assim, S2 é instaurado como sujeito do QUERER Ov13'.

No parágrafo 47, há uma embreagem de enunciador, por meio da qual S1 propõe um contrato com S2 de oposição ao $\overline{\mathrm{Ov} 13^{\prime}}$. Esse parágrafo pode ser caracterizado como o de fracasso das instituições político-administrativas do Brasil, pois S1 confessa que o regime parlamentar exige uma sólida estrutura administrativa e grande esclarecimento e organização política, o que o Brasil não possui no momento.

O tempo do Brasil, segundo S1, é o do presente com projeções para o futuro. O espaço do Brasil, segundo S1, não é apenas o Brasil, mas o mundo. Ou seja, localiza o país dentro de uma conjuntura internacional à qual a nação não pode ficar alheia nem negar sua participação. Desse modo, a conjuntura internacional passa a ser Destinador-julgador (D5), que observa o Brasil e cobra-lhe atividades no plano econômico. 


\section{SEGMENTO 5}

S1 retoma o tema já levantado no segundo segmento: "O que chamam crise, hoje, em nosso país, se procurarmos aprofundar a nossa análise, é na verdade mudança". Procura aqui, porém, desidentificar mudança e crise. Ou melhor, tenta negar a existência de uma crise, seguindo direção oposta àquela que indicou no primeiro parágrafo do segundo segmento, onde "confundia" ( $\operatorname{con}=$ reunião; fundia $=$ fusão, sincretismo) mudança e crise. Assim, entra em contradição com o que afirma no parágrafo 23 (terceiro segmento), onde diz textualmente: "E o meu gesto é motivado pelo desejo de amplo entendimento, para conciliar, para possibilitar decisões que possam assegurar que o Brasil saia da crise, dando eu próprio um exemplo de desambição".

No parágrafo 52, temos: "Há coisas que não pertencem a uma geração, mas a todas as gerações, a todos os tempos: uma Constituição moderna, defensora dos direitos sociais, dos interesses do Brasil, dos direitos humanos, uma Constituição para servir uma sociedade pluralista, aberta e mais justa". Com a primeira frase, S1 opõe-se à limitação da Constituição a um espaço e tempo definidos, limitados. Deseja que ela se realize em espaço e tempo abertos, em todos os espaços e tempos e, ao mesmo tempo, em nenhum deles. Ao desejar assim, ele próprio define a realização da Constituição no espaço e tempo de utopia. Utopos é o lugar do nenhum lugar, é o tempo de nenhum tempo. É o onde e o quando tudo e nada se realizam.

Em: "O Presidente não é o autor das dificuldades: ao contrário, ele está obstinadamente empenhado em superá-las” há uma embreagem de enunciador até então não utilizada. S1 se refere a si mesmo em terceira pessoa do singular (ele), criando uma distância entre Presidente e as dificuldades.

Reforça a idéia da disjunção com a causa dos problemas - (S1 U $\overline{\text { Ov15 }}$ ) - embreando para a primeira pessoa do singular (eu) e, em seguida, debreando para a primeira pessoa do plural novamente. Assim, torna-se sujeito de um saber firme: "E tenho certeza de que juntos nós venceremos todas as dificuldades". Nova embreagem de enunciador é utilizada e, agora, há a tentativa de estabelecimento de contrato com S2, no sentido de firmar a idéia de que os dois se encontram em sincretismo na luta contra as dificuldades (Ov16): S1 $\rightarrow$ (S3 Ov16). 
"Temos de resolver, urgentemente, os problemas da dívida externa e da economia interna". "É impossível conviver com estas taxas de inflação, de juros e com a carestia”. Nesses dois parágrafos, S1 retoma o problema da economia brasileira e lembra a dívida externa. A lembrança desta última concatena-se com a instauração, no segmento anterior, do D5. Ou seja, o problema da dívida externa deixa claro por que S1 instaura a conjuntura mundial como Destinador-julgador que observa o país e cobra-lhe atividades, no sentido de cumprir suas obrigações para com os credores internacionais. Desse modo, dentro do programa econômico que S1 deseja que S3 realize, está contemplado o pagamento da dívida externa.

"Hoje é o começo. Outros passos virão". "A mensagem é uma só: a hora é de fé e resistência ao pessimismo". O passado é apagado. O Brasil começa uma nova vida hoje. O importante é o amanhã, que deve ser visto com fé e otimismo. É assim que S1 deseja que S2 veja o país, sua história e tarefas. Desse modo, investe-se do papel de Destinador que tem o PODER de FAZER S2 CRER na esperança. As tarefas são as já atribuídas pelo D3 (S1) a S2, que é modalizado, desta forma, por um SABER que lhe dá um DEVER de realizar a narrativa que S1 propôs, no sentido de satisfazer seu QUERER (saída da crise).

"Que Deus proteja o Brasil". Por meio desta frase optativa, S1 aponta o início de uma nova narrativa na qual todos que eram Destinadores até então, inclusive S1, passam a ser simples sujeitos, subordinados a um Destinador soberano e onipresente, que se sobrepõe a qualquer poder ou vontade (D6 = Deus).

Essa frase permite diversas interpretações. Uma delas seria a de que S1 busca um sincretismo com S2 apoiando-se em valores socioculturais brasileiros, mais especificamente no plano religioso. Procura FAZER S2 CRER que S1 é um ser humano que, embora tenha um PODER FAZER, esse PODER FAZER só é possivel com o apoio de S2 e ambos investidos de competência por D6.

Uma outra outra interpretação possível seria, no entanto, a constatação do fracasso total da performance da sociedade brasileira e do próprio S1, no que tange à solução dos problemas que os afetam e à conquista de uma sociedade mais justa. 


\section{Conclusão}

Por todo o exposto, o discurso do Presidente Sarney pode ser caracterizado como o discurso do FRACASSO:

- FRACASSO de S1 que tem um QUERER, um SABER, um DEVER, mas não tem um PODER FAZER SER no que tange ao mandato e à situação econômica;

- FRACASSO da mudança que S2 (povo brasileiro) desejava e pela qual lutou: o resultado foi a crise;

- FRACASSO da estrutura política e administrativa do país, que não pode sequer optar pelo regime parlamentar por não ter condições estruturais mínimas para tanto.

O fracasso, porém, é a condição da vitória e, diante do quadro em que o país se encontra, essa vitória, segundo S1, só pode ser conquistada por meio de uma nova narrativa - cujos programas ele já explicitou e que tenha, como Destinador, Deus.

Segundo essa perspectiva, a narrativa que a sociedade brasileira e o próprio $\mathrm{S} 1$ desenvolvem hoje nada mais é do que o momento da aquisição de competência por parte de S3 para a performance a ser realizada em outra narrativa (cujo Destinador maior é Deus), no futuro.

Desse modo, fica claro que o discurso do Presidente é apenas um momento dentro de um processo em curso, que se iniciou no passado, percorre o presente e se projeta no futuro. Colaboram, na prova desta tese, as embreagens e debreagens espaço-temporais.

É também por meio do mecanismo de embreagens e debreagens de enunciador que S1 procura estabelecer um contrato com S2 para persuadilo a aderir à sua proposta de narrativa a ser seguida.

A intimidação, dentro do processo manipulatório, é também utilizada para que S1 atinja seus objetivos em relação a S2.

Por meio de oposições, S1 cria anti-objetos de valor e anti-sujeitos. Procurando um sincretismo com S2 e alinhando-se ao lado dos Ov, S1 procura fazer com que tudo e todos que se oponham a ele, oponham-se obrigatoriamente a S2 e ao anseio de uma sociedade mais justa. Porém, em 
alguns momentos, o próprio S1 acaba, no nível discursivo, na trincheira oposta. Isto é, apresenta-se como anti-sujeito ou anti-Destinador daquilo que ele diz defender.

Durante o discurso todo, S1 tenta FAZER S2 CRER que possui um SABER e um DEVER de FAZER SER seu QUERER. Mais do que isso, S1 tenta FAZER S2 CRER que seu QUERER é igual ao QUERER de S1 e, portanto, S1 tenta FAZER S2 FAZER o que S1 quer, ou seja, que S2 adira à proposta de narrativa de $\mathrm{S} 1$.

Em sendo assim, o discurso todo pode ser caracterizado como uma proposta de pacto político de apoio ao governo, uma vez que ele propõe a união de todos os setores da sociedade, tendo o governo como mediador para se alcançar um objetivo comum. Essa união pressupõe um acordo político mínimo, que para S1 é a definição da duração do mandato presidencial em cinco anos. Nesse sentido, é necessário um acordo em torno do mandato de cinco anos para que o objetivo comum seja alcançado.

Essa é, fundamentalmente, a grande marca do pronunciamento do Presidente: a tentativa de negociação a respeito do mandato. $\mathrm{O}$ percurso da negociação dá-se de três modos diferentes:

$\mathrm{F}[\mathrm{S} 1 \rightarrow((\mathrm{S} 1+\mathrm{S} 5) \cap \mathrm{Ov} 7)] / / \mathrm{F}[\mathrm{S} 1 \rightarrow(\mathrm{S} 6 \cap \overline{\mathrm{Ov} 7})] / / \mathrm{S} 1 \rightarrow(\mathrm{St} \cap \mathrm{Ov} 7)$

(1) O discurso inicial é o da democracia e ponderação. S1 convoca os partidos a discutir a questão da duração do mandato. O tempo é o passado e o nível é o do SER, já que para isso S1 tem o PODER para FAZER SER;

(2) O discurso passa a ser autoritário, não polêmico. O tempo é o presente e o nível é o do PARECER, pois S1 NÃO tem PODER para FAZER SER. Passa a anti-sujeito/ anti-Destinador.

(3) Discurso autoritário fracassado. Retomada do exame do assunto. Proposta de negociação com base já estabelecida: mandato de cinco anos. Portanto, negociação viciada, limitada, não-negociação: pacto político de apoio ao governo.

O segmento que trata do regime governamental seria considerado apenas como um anexo à discussão principal, se olhado dentro de uma perspectiva limitada. Melhor explicando, se o discurso do Presidente for 
considerado um começo e fim em si próprio, o segmento em questão estaria deslocado da discussão central. No entanto, se o discurso for considerado no seu conjunto, enquanto parte de um processo em curso, o assunto do regime governamental tem seu espaço político ampliado e sua importância devidamente considerada.

Por fim, o pronunciamento de Sarney caracteriza-se pela sobremodalização: é ao mesmo tempo discurso político, pedagógico, religioso e da propaganda.

Após a análise que propomos neste artigo colocamo-nos a questão: os mecanismos de manipulação, contramanipulação e persuasão descritos teriam sido usados apenas circunstancialmente pelo Presidente Sarney na época do seu discurso ou continuam presentes, de um modo ou de outro, nos discursos políticos notadamente presidenciais, no Brasil?

E-mail: lidia@lem.ibilce.unesp.br

Recebido em janeiro de 2002

Aprovado em julho de 2002

\section{Bibliografia de Base}

COURTES, J. 1976. Introduction à la sémiotique narrative et discursive. Paris: Hachette.

Everaert-Desmedet, N. 1984. Semiótica da narrativa. Coimbra: Almeidina.

Greimas, A.J.; E. Landowski 1986. Análise do discurso em ciências sociais. São Paulo: Global

Greimas, A.J.; J. Courtes 1984. Dicionário de semiótica. São Paulo: Cultrix. 


\section{ANEXO}

\section{Íntegra do pronunciamento do Presidente José Sarney, feito em 18.05.1987, publicado no jornal O Estado de São Paulo em 19.05.1987}

\begin{tabular}{|c|c|}
\hline \multicolumn{2}{|c|}{ SEGMENTO 1} \\
\hline 1. & Brasileiras e brasileiros, boa noite. \\
\hline 2. & $\begin{array}{l}\text { Estou aqui para um comunicado da maior importância para os rumos políticos } \\
\text { do nosso país. }\end{array}$ \\
\hline 3. & Brasil me conhece. Sabe que não sou de decisões precipitadas. \\
\hline 4. & $\begin{array}{l}\text { Por formação e experiência, eu medito, pondero, analiso, ouço e sou prudente } \\
\text { antes de decidir. }\end{array}$ \\
\hline 5 . & $\begin{array}{l}\text { Esta palavras eu as pronunciei em } 22 \text { de julho de } 1985 \text {. Quem esperava um } \\
\text { Presidente autoritário, soube, logo de início, que esse Presidente não seria eu. }\end{array}$ \\
\hline 6. & $\begin{array}{l}\text { Afirmei também: acerto e posso cometer equívocos. Sensibilizado do erro, eu } \\
\text { nele não permaneço. }\end{array}$ \\
\hline & $\begin{array}{l}\text { Nesta noite, eu quero acrescentar: quando me convenço de que estou no cami- } \\
\text { nho certo, eu dele não me afasto, quaisquer que sejam as dificuldades, conseqü- } \\
\text { ências ou lutas. }\end{array}$ \\
\hline 8. & $\begin{array}{l}\text { A responsabilidade que o destino me colocou à frente é minha e dela não vou } \\
\text { fugir. }\end{array}$ \\
\hline 9 . & $\begin{array}{l}\text { Sem abdicar da autoridade de chefe da nação, exerço um governo democrático e } \\
\text { aberto. Não me tem faltado para isso espírito de tolerância, considerado muitas } \\
\text { vezes até excessivo por muitas pessoas. }\end{array}$ \\
\hline 10 . & $\begin{array}{l}\text { Assim também como não me tem faltado a necessária e a justa paciência que } \\
\text { devem ter os homens de Estado. }\end{array}$ \\
\hline & $\begin{array}{l}\text { Sou um homem que sempre viveu a vida partidiária, por isso entreguei aos polí- } \\
\text { ticos a coordenação política do governo através da Aliança Democrática, porque } \\
\text { eu sei que sem partidos não existe democracia. Com eles tenho governado em } \\
\text { estreita comunhão. }\end{array}$ \\
\hline
\end{tabular}

\section{SEGMENTO 2}

12. Brasileiras e brasileiros,

13. Com a franqueza com que sempre me dirigi às brasileiras e brasileiros, devo admitir que nós vivemos uma fase de múltiplas, acentuadas e grandes dificuldades. Queríamos e lutamos por um governo de mudanças. E o Brasil mudou. Acontece que mudança e crise se confundem nos momentos históricos de transição, como o momento que nós vivemos. 
14. Para resolver os problemas que nos envolvem, devemos ter solução adequada ao primeiro deles, que é um problema de natureza política, e que está na raiz de todos os outros problemas: a duração do mandato presidencial.

15. Convoquei os partidos para conjuntamente examinarmos o assunto, fora dos interesses pessoais de candidaturas de grupo, de facções e de ambições, vendo o problema unicamente em função do interesse nacional. Há cinco meses espero uma definição.

16. Compreendo as dificuldades dos nossos líderes.

17. Contudo, cheguei à conclusão de que a nação não pode ficar imobilizada na perplexidade desse embate. Porque acima da Aliança Democrática, acima dos partidos, está o interesse do Brasil, que eu jurei defender.

18. É da lei: todos os detentores de mandato - senadores, deputados, governadores, prefeitos, vereadores - o são por tempo determinado, fixado antes de sua eleição.

19. Tancredo Neves e eu, ao sermos eleitos, nós não fugimos à regra. Nós fomos eleitos para um mandato de seis anos.

20. A indefinição que se procurou criar e que vem se arrastando não deve e não pode perdurar, sob pena de graves prejuízos para o país.

21. Ela solapa a hierarquia e o serviço público, dificultando a formulação da política interna e a defesa dos interesses externos do Brasil.

\section{SEGMENTO 3}

22. Brasileiras e brasileiros,

23. Venho falar claramente sobre este assunto. Desejo comunicar a todos, a todas as brasileiras e brasileiros, que eu abrirei mão de um ano de meu mandato e o exercerei pelo prazo de cinco anos. E meu gesto é motivado pelo desejo de amplo entendimento, para conciliar, para possibilitar decisões que possam assegurar que o Brasil saia da crise, dando eu próprio um exemplo de desambição.

24. Deixarei, portanto, o governo em 1990. Até lá, no entanto, exercerei plenamente o mandato que me foi confiado, que jurei defender na forma da Constituição e que consta de um diploma expedido pelo Congresso Nacional.

25. Com a autoridade e a isenção de quem abdicará de um ano de seu mandato, defendo junto aos constituintes a fixação de um idêntico mandato de cinco anos para os próximos Presidentes, conforme previa a Constituição de 1946.

26. mandato de quatro anos considero que não convém à consolidação do processo democrático e se o adotássemos, estaria aberta agora a campanha presidencial, com prejuízo para o país, para a transição democrática, para os trabalhos da própria Assembléia Nacional Constituinte.

27. Acresce ainda que 1988 será o ano de adaptações das constituições estaduais; de elaboração das leis eleitorais, das leis partidiárias, das leis complementares e revisão de toda a legislação ordinária determinadas pela nova Constituição, além das eleições municipais que teremos de realizar. 
28. No ano seguinte, em 1989, comemoraremos o centenário da fundação da República e comemoraremos o centenário com a eleição que eu presidirei, do meu sucessor.

29. Aproveito este instante para determinar aos auxiliares de meu governo, como delegados de minha confiança, que considerem encerrada essa discussão. Dos partidos políticos eu espero solidariedade.

30. Aos governantes dos Estados, aos Deputados e Senadores constituintes peço apoio e compreensão.

31. Para que o processo democrático possa se consolidar, é essencial demonstrar que o poder civil tem condições de governar.

32. A governabilidade do poder civil depende, porém, de uma inalterável definição do prazo que estabelece a periodicidade do mandato.

33. Do contrário, o governo não terá horizontes para seus programas, para tomar decisões de maior profundidade. A indefinição paralisa, as crises se ampliam e fica uma impressão geral na sociedade de imobilidade. A explosão descontrolada dos preços, que angustia nossa população, é, no fundo, fruto dess indefinição política.

34. Não tenham dúvidas de que, antes de serem um problema econômico, a inflação e a recessão são problemas políticos. Sem a recomposição do poder político, não há possibilidade de evitar o agravamento da inflação e, mais cedo ou mais tarde, o retorno indesejado da recessão.

35. Se nós não formos capazes de chegar a um acordo sobre as bases mínimas para um entendimento político, nós não teremos a menor possibilidade de conduzir um esforço efetivo para deter a carestia e retomar o desenvolvimento econômico. Contra a inflação é necessária a união de todos. É necessária a união firme de todos nós.

36. Como está, a inflação não apenas reduzirá cada vez mais o poder de compra, mas poderá - com que tristeza eu não tenho de dizer - poderá até mesmo provocar a recessão.

37. Não estamos sob nenhuma ameaça ao processo democrático. Mas devemos nos antecipar a qualquer deterioração da situação nacional.

38. Eu renovo, mais uma vez na perigrinação constante em torno dessa idéia, a necessidade de entendimento de preços e salários no processo de produção - com a participação e coordenação do governo, que deverá fazer a sua parte, para que a corrida inflacionária possa ser completamente detida.

39. Todos os partidos, no Congresso Nacional, devem desempenhar uma importante tarefa e prestar um grande trabalho ao país, mobilizando-se para esta causa.

40. que proponho, assim, não é um pacto político de apoio ao governo. Eu proponho uma agenda ampla, social e política de transição democrática, uma co-responsabilidade com o Executivo, para a superação dos problemas de consolidação do nosso processo democrático.

41. Sei, com grande pesar, que o povo está passando por sérias e por grandes dificuldades.

42. Os Estados encontram-se em situação difícil. Os Governadores lutam contra uma situação financeira de anarquia. Eles precisam de tempo, eles precisam de 
tempo para trabalhar. As greves neste instante prejudicam os interesses dos próprios trabalhadores e dos funcionários públicos.

\begin{tabular}{ll}
\hline SEGMENTO 4 \\
\hline 43. & Brasileiras e brasileiros, \\
\hline 44. & $\begin{array}{l}\text { Eu, antes de terminar, quero transmitir a todos também a minha opinião de } \\
\text { cidadão a respeito do regime do governo debatido na Constituição. }\end{array}$ \\
\hline 45. & Sou favorável a um sitema presidencialista que incorpore uma participação forte \\
& do Congresso Nacional nas tarefas de governo. \\
\hline 46. & Depois de ter optado pelas eleições diretas - incluídas hoje na Constituição por \\
mensagem de minha iniciativa - o povo brasileiro dificilmente aceitaria que lhe \\
retirassem o poder de constituir seu governo.
\end{tabular}

\section{SEGMENTO 5}

49. Brasileiras e brasileiros,

50. Não seremos uma autarquia num mundo desejoso de participação do Brasil, como uma das grandes potências econômicas do Ocidente.

51. É para este mundo, para a infância e juventude brasileira, para os homens do futuro, que está sendo elaborada a nossa nova Constituição.

52. Há coisas que não pertencem a uma geração, mas a todas as gerações, a todos so tempos: uma Constituição moderna, defensora dos direitos sociais, dos interesses do Brasil, dos direitos humanos, uma Constituição para servir uma sociedade pluralista, aberta e mais justa.

53. O que chamam de crise, hoje, em nosso país, se procurarmos aprofundar a nossa análise, é na verdade mudança. Mudança a que muitos resitem.

54. Presidente não é autor das dificuldades: ao contrário, ele está obstinadamente empenhado em superá-los. Eu tenho certeza de que juntos nós venceremos todas as dificuldades. Este é o primeiro passo. Temos de resolver urgentemente, os problemas da dívida externa e da economia interna.

55. É impossível conviver com estas taxas de inflação, de juros e com a carestia . Hoje é o começo. Outros passos virão. A mensagem é uma só: a hora é de fé e resistência ao pessimismo. Que Deus proteja o Brasil.

56. Muito obrigado. Boa noite. 